\title{
A Common Single Nucleotide Polymorphism Alters the Synthesis and Secretion of Neuropeptide $\mathrm{Y}$
}

\author{
Gregory C. Mitchell, ${ }^{\star}$ Qian Wang, ${ }^{\star}$ Prabhu Ramamoorthy, and Matthew D. Whim \\ Department of Biology, Pennsylvania State University, State College, Pennsylvania 16802
}

\begin{abstract}
A single nucleotide polymorphism (SNP) in the neuropeptide Y gene has been associated with elevated serum lipid levels and cardiovascular disease. The polymorphism (T1128C) changes the seventh amino acid in the prohormone from leucine to proline. It has been speculated this alters neuropeptide Y (NPY) synthesis, trafficking, or secretion. We tested this hypothesis by expressing the mutant and wild-type prohormones in CNS neurons and endocrine cells. Synthesis and trafficking were followed using immunocytochemistry and fluorescent protein-tagged fusion constructs. Mutant prohormone was synthesized and entered the regulated secretory pathway. When expressed in endocrine cells, wild-type and mutant proteins were found in the same large dense core granules. However, the T1128C polymorphism altered the degree of copackaging, and, on average, individual granules contained more mutant prohormone. This was not attributable to codon bias but to the change in prohormone sequence. Global prohormone targeting was normal, because in hippocampal neurons, the polarized distribution of the mutant prohormone was indistinguishable from the wild-type. When secretion was measured from chromaffin cells, brief depolarizations triggered peptide secretion, confirming the entry of the mutant prohormone into the regulated secretory pathway. However, cells that expressed the mutant protein had increased levels of peptide secretion. We conclude that the T1128C polymorphism alters the packaging and secretion of NPY. In contrast to SNPs in other prohormones, we could not find a phenotype until the prohormone was tracked at the single granule level. These results are consistent with studies showing the T1128C polymorphism has pleiotropic effects.
\end{abstract}

Key words: neuropeptide; single nucleotide polymorphism; secretion; trafficking; large dense core granule; chromaffin cell

\section{Introduction}

The human genome contains millions of single nucleotide polymorphisms (SNPs) or differences at the single nucleotide level between individuals. Although the majority of SNPs are found outside of coding regions, such polymorphisms are of interest because genetic variability between individuals affects susceptibility to many diseases. To identify the sites of variation, large scale mapping studies are being used to identify SNPs associated with numerous diseases including heart disease (Larson et al., 2007).

After the identification of a consequential polymorphism, an important step is to determine the molecular mechanism that causally explains the disease association. In the nervous system, functional SNPs have been identified in genes encoding receptors, transporters, ion channels, and neuromodulators (MazeiRobison et al., 2005; Vitko et al., 2005; Hasan et al., 2007; Kessler et al., 2007). One recent success has been the isolation of the G196A (Val66Met) polymorphism in the BDNF gene. This poly-

\footnotetext{
Received Jan. 25, 2008; revised 0ct. 18, 2008; accepted Nov. 14, 2008.

This work was supported by National Institutes of Health Grants 5R21 NS047543 and 1R56 DK080441 and by start-up funds from Pennsylvania State University. We thank Dr. June Liu for critically reading this manuscript, Dr. David Braun for advice on Western blotting, and Drs. R. Y. Tsien (University of California, San Diego) and A. Miyawaki (RIKEN Brain Science Institute, Wako-city, Japan) for mRFP1 and Venus CDNA's.

*G.C.M. and Q.W. contributed equally to this work.

Correspondence should be addressed to Matthew D. Whim, Department of Biology, 208 Mueller Building, Pennsylvania State University, State College, PA 16802. E-mail: mdw13@psu.edu.

D0I:10.1523/JNEUROSCI.0343-08.2008

Copyright $\odot 2008$ Society for Neuroscience $\quad$ 0270-6474/08/2814428-07\$15.00/0
}

morphism leads to somatic retention of the mutant prohormone, a reduction in BDNF secretion and memory impairment (Egan et al., 2003).

To date, only a handful of polymorphisms for modulators like BDNF have been functionally studied. An intriguing example in another neuropeptide is the T1128C SNP in the neuropeptide Y (NPY) gene (Karvonen et al., 1998). This polymorphism was initially associated with elevated levels of serum cholesterol but has also been linked to atherosclerosis and diabetes (Niskanen et al., 2000; Ukkola and Kesaniemi, 2007). The pleiotropic phenotype presumably reflects the widespread distribution of NPY. In the periphery, NPY potently regulates blood pressure, whereas central NPY modulates many behaviors, including feeding (Kuo et al., 2007a). The T1128C polymorphism in the NPY gene changes the seventh amino acid in the prohormone from a leucine to proline. Its location in the NPY signal sequence is not expected to change the sequence of mature NPY but has been suggested to lead to a change in the synthesis, trafficking, and/or secretion of the peptide (Karvonen et al., 1998; Kallio et al., 2001). However, this idea has not been thoroughly examined.

Here, we directly test this hypothesis by comparing the expression of the mutant and wild-type (wt) prohormones. We find that T1128C does not prevent synthesis or trafficking of the NPYcontaining dense core granules. However, the polymorphism alters the packaging and secretion of NPY. Our results suggest a molecular mechanism that may underlie the broad phenotype of the T1128C polymorphism. 


\section{Materials and Methods}

Cell culture. AtT-20 cells and mouse chromaffin cells postnatal days 18-25 (P18-P25) were cultured as described previously (Whim and Moss, 2001; Whim, 2006) and transfected using Lipofectamine 2000 after 1-2 days in vitro (DIV). Hippocampal neurons from C57BL/6 mice (P1P3) were grown on cortical astrocytes and maintained in Neurobasal, 2\% B27 supplement, $0.4 \mathrm{~mm}$ L-glutamine. After 5-8 DIV, cultures were transfected in DMEM/1 mM kynurenic acid with $1.5 \mu \mathrm{g}$ vector DNA using calcium phosphate. Neurons were fixed $48 \mathrm{~h}$ later.

Molecular biology. PCR used standard techniques. pNPY-red fluorescent protein (RFP) and pNPY-Venus were made in pcDNA3.1 (Invitrogen) by fusing the fluorescent protein to the C terminus of NPY immediately upstream of the KR dibasic cleavage site. This ensured that the fusion protein remained intact during prohormone processing. Sitedirected mutagenesis was subsequently used to create the T1128C or L7P mutations (see below). pIRES-NPY constructs were made in pIRES2AcGFP1 (Clontech). All constructs (supplemental Fig. 1, available at www.jneurosci.org as supplemental material) were based on the human NPY prohormone which had been modified by adding two copies of the FMRFamide peptide to the $3^{\prime}$ end (Whim, 2006). Constructs were confirmed by sequencing. Plasmid concentrations were measured using a NanoDrop spectrophotometer.

The observed T1128C polymorphism (Karvonen et al., 1998) changes CTG (leucine) to CCG (proline). This is the least frequently used proline codon (a frequency of 6.2 per thousand). Constructs that incorporate this codon are termed T1128C. Constructs using the most frequently employed proline codon (CCC; 19.8 per thousand) are termed L7P. For comparison, the leucine CTG codon has a frequency of 39.6 per thousand. These frequencies are for human codon usage; the mouse values are comparable.

Immunocytochemistry. Cells were processed as described previously (Whim and Moss, 2001). When comparing prohormone copackaging (see Fig. 2), AtT-20 cells were transfected, then after 48 h, incubated with $10 \mu \mathrm{M}$ cycloheximide for $1 \mathrm{~h}$ to limit endoplasmic reticulum (ER)derived fluorescence (Sobota et al., 2006), before fixation in paraformaldehyde. Primary antibodies were mouse anti-carboxypeptidase E (CPE) (1:600; BD Transduction Laboratories), rabbit anti-NPY (1:200; Peninsula Laboratories), rabbit anti-FMRFamide (1:200; Peninsula Laboratories), mouse anti-GM130 (1:1000; BD Transduction Laboratories), and mouse anti-microtubule-associated protein 2 (MAP2) (1:200; Millipore). Secondary antibodies were donkey anti-rabbit Alexa 488 (1:200; Invitrogen), goat anti-mouse FITC, donkey anti-mouse tetramethylrhodamine isothiocyanate (TRITC), donkey anti-rabbit TRITC (all 1:50; Jackson ImmunoResearch Laboratories). Images were taken using a Nikon TE2000U microscope with a $60 \times(1.4 \mathrm{NA})$ oil-immersion objective and a Retiga 1300 monochrome camera.

Image analysis. Puncta were picked in each fluorescence channel using the same area of interest (AOI). A punctum was first identified in the green channel then the AOI transferred to the red channel. Image-Pro Plus 5.1 (Media Cybernetics), OriginPro7, and Excel were used for data analysis. Statistical significance was assessed using ANOVA and Kolmogorov-Smirnov tests. Each experiment contained sister cultures of matched wild-type and T1128C or L7P transfected AtT-20 cells. Analysis was performed blind to genotype.

FMRFamide-tagging release experiments. Chromaffin cells were transfected with $0.75 \mu \mathrm{g}$ pFaNaCh and $0.75 \mu \mathrm{g}$ pIRES-NPY wild-type/T1128C prohormone. Whole-cell voltage-clamp recordings were made as described previously (Whim, 2006), 2-3 d after transfection. The pipette solution contained (in mM) $120 \mathrm{Cs}$ acetate, $15 \mathrm{CsCl}, 5 \mathrm{NaCl}, 10$ HEPES, 4 MgATP, 0.3 NaGTP, 0.2 Na cAMP, pH 7.2 with CsOH. The extracellular solution contained $135 \mathrm{NaCl}, 3 \mathrm{KCl}, 2 \mathrm{CaCl}_{2}, 1 \mathrm{MgCl}_{2}, 10 \mathrm{HEPES}, 11$ glucose, $\mathrm{pH}$ 7.3. Each experiment contained matched sister wild-type and T1128C-transfected cells, and experiments were performed blind to genotype.

\section{Results}

A priori, the Leu7Pro polymorphism could alter the synthesis, trafficking, and/or secretion of neuropeptide Y. We investigated each of these possibilities.

\section{L7P and wild-type NPY prohormones are sorted similarly in At $\mathrm{T}-20$ cells}

AtT-20 cells, an endocrine cell line, were transfected with an IRES-GFP vector encoding the mutant or wild-type NPY prohormone. AtT-20 cells can synthesize peptides but do not endogenously contain NPY (Dickerson et al., 1987). Transfected cells identified by cytoplasmic GFP had punctate NPYimmunoreactivity (NPY-ir) regardless of whether they expressed the mutant or the wild-type NPY prohormone (Fig. 1A).

To study the trafficking of the wild-type and mutant prohormones, we subsequently used constructs in which NPY was fused in frame to either Venus or RFP. Expression of NPY-RFP (and NPY-Venus) revealed a punctate distribution that matched the distribution of NPY-ir, validating the use of these fusion proteins (Fig. 1B).

Peptides like NPY enter the regulated secretory pathway via the endoplasmic reticulum and Golgi network before storage in dense core granules (Dikeakos and Reudelhuber, 2007). If L7P NPY is processed via the same pathway, it should be found in these compartments. In fact, both mutant and wild-type NPYVenus colocalized with GM130-ir (Fig. 1C), a marker of the cisGolgi (Nakamura et al., 1995). Mutant and wild-type NPY-RFP also colocalized with carboxypeptidase $\mathrm{E}$, a marker of peptidergic dense core granules (Fig. 1D). This enzyme cleaves many peptide prohormones (Fricker, 1988). There was no difference in the degree of colocalization of the wild-type and mutant NPY-RFP prohormones with $\mathrm{CPE}(3.4 \pm 0.9$ vs $3.3 \pm 1.5$, respectively, mean red: green punctal fluorescence intensity $\pm \mathrm{SD}, 55$ puncta analyzed from $n=3$ cells, $p=0.93$ ).

Thus, the L7P NPY prohormone appears to be targeted to the regulatory secretory pathway in a similar manner to the wild-type prohormone. Western blot analysis confirmed that the polymorphism did not prevent synthesis of the NPY prohormone (supplemental Fig. 2, available at www.jneurosci.org as supplemental material).

\section{L7P and wild-type NPY prohormones enter the same dense core granules}

The majority of the L7P carriers are heterozygous (Karvonen et al., 1998). Thus, in vivo neurons are likely to contain mutant and wild-type prohormone. To mimic these conditions, AtT-20 cells were cotransfected with wt NPY-Venus plus L7P NPY-RFP. Control cells were cotransfected with wt NPY-Venus plus wt NPYRFP. Complete overlap of red and green puncta was observed in both conditions, indicating that mutant and wild-type prohormones are copackaged in the same dense core granules. This can be seen in an intensity line scan (Fig. 2A).

At this stage, the processing of the L7P and wild-type prohormones appeared indistinguishable, although this approach can reveal the effect of SNPs on other prohormones (Egan et al., 2003). However, differences in packaging are sometimes quantitative (Castle et al., 1997). Thus, we next measured the relative amounts of the mutant and wild-type prohormones in single granules.

\section{Differential copackaging of L7P and wild-type NPY prohormones}

AtT-20 cells were cotransfected with wild type, and mutant prohormones were tagged with either Venus or RFP. Two days after transfection, the cells were fixed and the intensity of individual puncta in the green and red channels was measured, then plotted as a cumulative ratio distribution (Fig. $2 B$, left). Because Venus and RFP might be synthesized at different intrinsic rates, control 

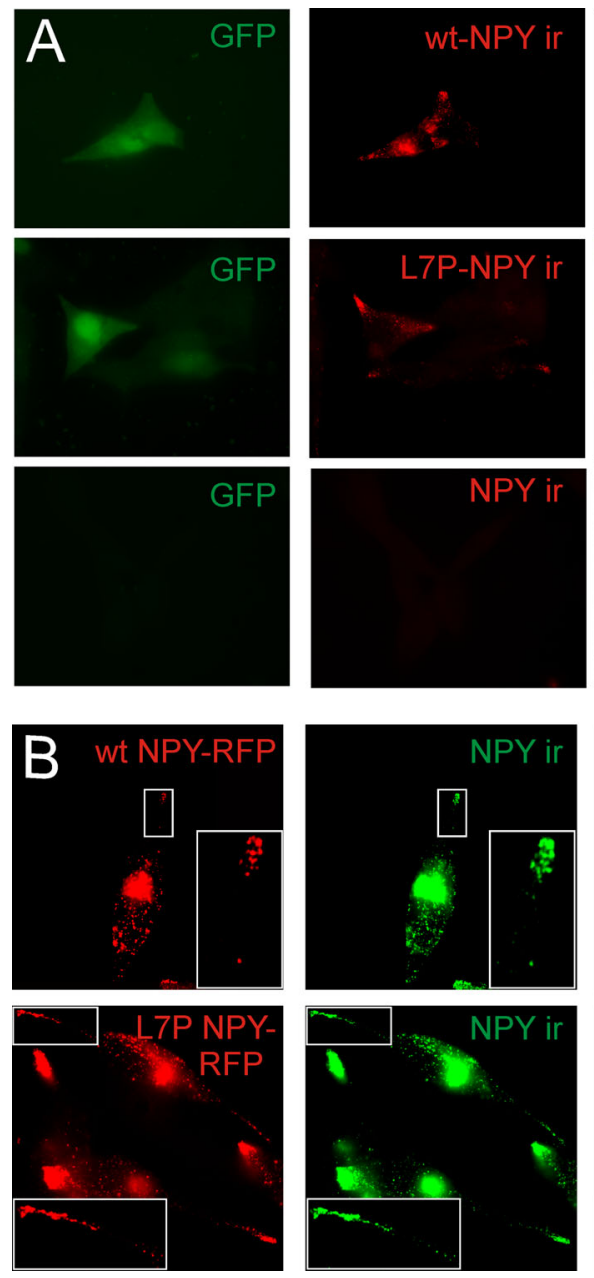
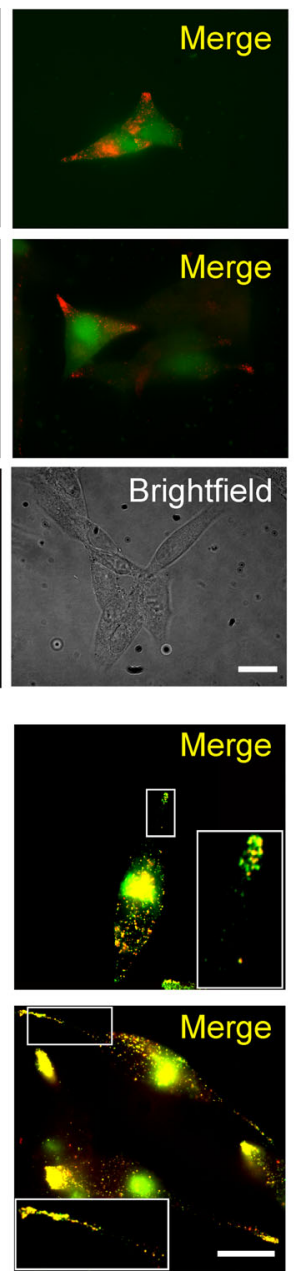
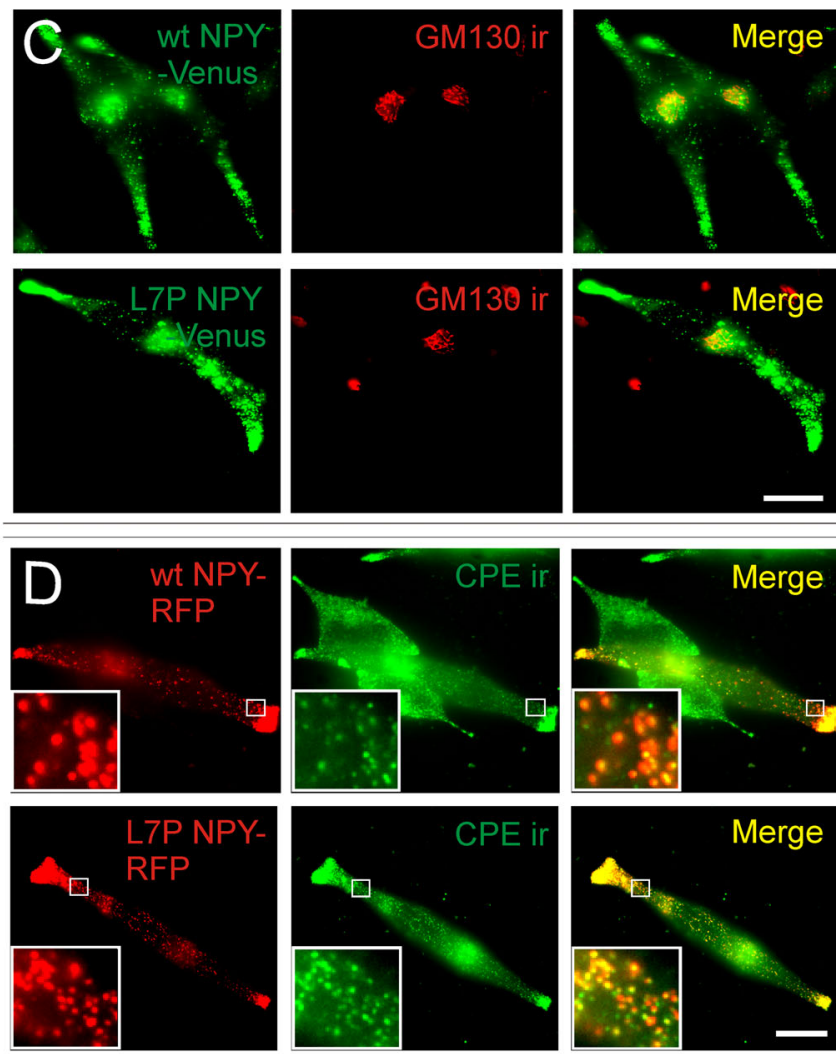

Figure 1. Colocalization of wt and L7P NPY prohormones with markers of the regulated secretory pathway. $A$, Expression of wt-NPY and L7P-NPY in AtT-20 cells. Transfected cells (GFP-positive) contained NPY-ir puncta indicating synthesis of wt and L7P NPY prohormones. Nontransfected cells (GFP-negative) do not synthesize NPY. $\boldsymbol{B}$, Cells expressing wt NPY-RFP or L7P NPY-RFP fusion proteins contained fluorescent puncta that colocalized with NPY-ir. C, wt NPY-Venus and L7P NPY-Venus fluorescence partially overlapped with GM130-ir. D, wt NPY-RFP and L7P NPY-RFP fluorescent puncta colocalize with CPE-ir puncta. Scale bars, $20 \mu \mathrm{m}$.

cells were cotransfected with the same prohormone separately tagged with both fluorescent proteins.

When comparing the results of these experiments, several features emerged. First, the fluorescence ratio distributions of the two control experiments overlapped (i.e., wt NPY-Venus plus wt NPY-RFP vs L7P NPY-Venus plus L7P NPY-RFP). This validates the approach, because it indicates that swapping the prohormone did not alter synthesis of the fluorescent tag. Second, the most right-shifted curve (i.e., the "greenest" puncta) came from cells expressing L7P NPY-Venus and wt NPY-RFP. In these cells, the L7P prohormone is thus expressed at higher levels. Third, the most left-shifted curve is the complementary result; these puncta contain relatively more RFP (which is now attached to the L7P prohormone). These results are consistent with dense core granules containing higher relative levels of the L7P prohormone.

The proline codon in the L7P mutant (CCC) was chosen to minimize a potential confounding effect attributable to codon usage (see Materials and Methods). To test whether the low frequency proline codon (CCG) actually found in the SNP had a similar phenotype, the experiment was repeated using T1128CVenus and T1128C-RFP. As seen in Figure 2C, and supplemental Fig. 3, available at www.jneurosci.org as supplemental material, the same relative expression levels of mutant and wild-type NPY prohormone were again found. We conclude that when cells are cotransfected with mutant and wild-type NPY prohormone, the dense core granules contain higher levels of mutant prohormone.

\section{Expression of L7P and wild-type NPY prohormones in} hippocampal neurons

To examine prohormone trafficking in an acutely isolated cell type, polarized hippocampal neurons were transfected with wt NPY-Venus or L7P NPY-Venus. The hippocampus endogenously contains NPY (Higuchi et al., 1988).

The distribution of native NPY was first determined (Fig. 3A). Cultures were stained for NPY and the dendritic marker MAP2. In NPY-ir neurons, the peptide showed a punctate distribution and was present in the cell body, dendrites and axon (as observed in cortical neurons in situ) (P. Ramamoorthy and M. D. Whim, unpublished observations). When hippocampal neurons were transfected with wt NPY-Venus or L7P NPY-Venus, a similar distribution was observed, with both mutant and wild-type NPY prohormone present in all these neuronal compartments (Fig. $3 B, C)$. There was also no significant difference in the axonal: dendritic ratio of fluorescently labeled puncta from cells transfected with wt NPY-Venus or L7P-Venus $[0.65 \pm 0.25$ (wt) vs $0.58 \pm 0.25(\mathrm{~L} 7 \mathrm{P})$; mean ratio $\pm \mathrm{SD}, n=19(\mathrm{wt}), n=24(\mathrm{~L} 7 \mathrm{P})]$.

Thus, the SNP in the NPY prohormone does not significantly alter the distribution of the NPY-containing dense core granules 

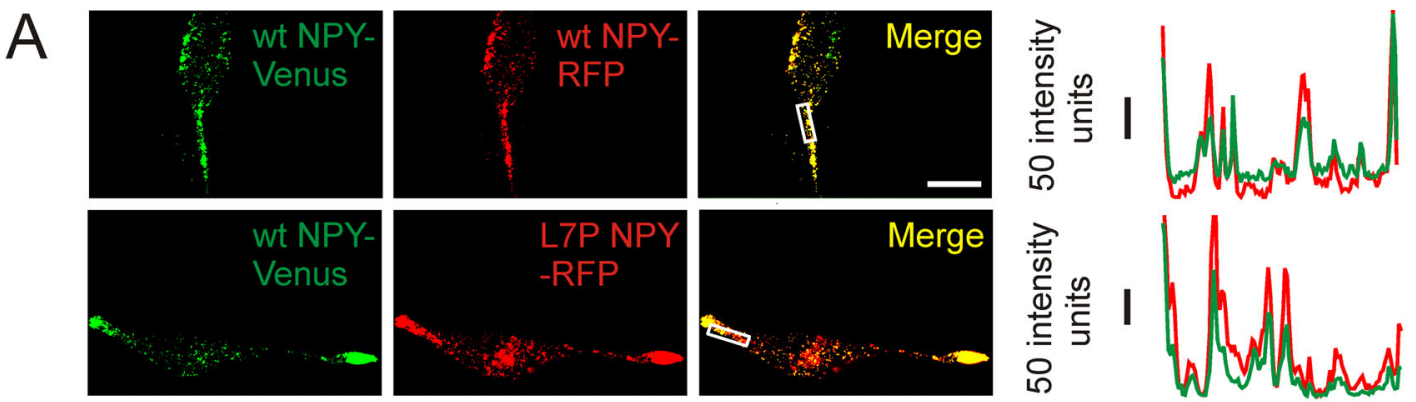
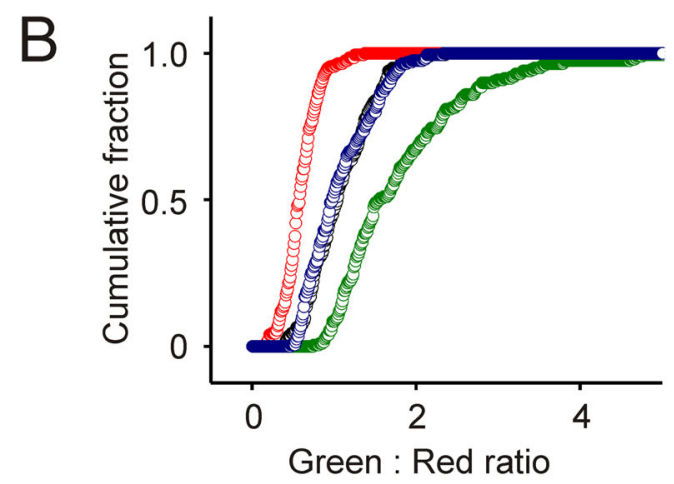

wt-Venus + L7P-RFP

wt-Venus + wt-RFP

L7P-Venus + L7P-RFP wt-RFP + L7P-Venus
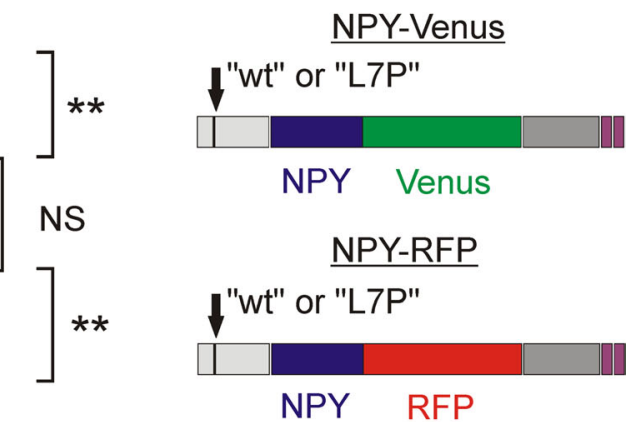
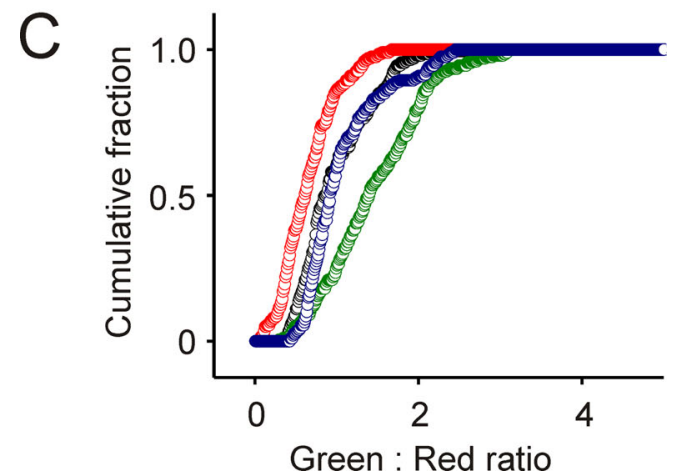

wt-Venus + T1128C-RFP

wt-Venus + wt-RFP

T1128C-Venus + T1128C-RFP

wt-RFP + T1128C-Venus

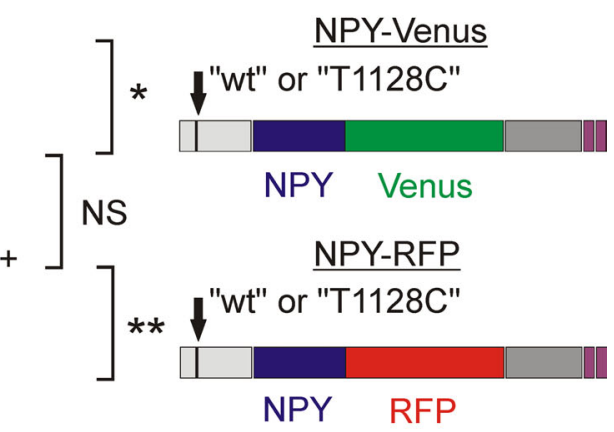

Figure 2. Differential copackaging of L7P and wild-type NPY prohormones. A, Cotransfection of AtT-20 cells with wt NPY-Venus and wt NPY-RFP (top) indicates that single puncta contain both fluorescent proteins. Line scan (right) through the center of the boxed area. A similar colocalization was seen when cells were transfected with wt NPY-Venus and L7P NPY-RFP (bottom). Scale bar, $15 \mu \mathrm{m}$. B, AtT-20 cells were cotransfected with wild type, and L7P NPY prohormones tagged with all combinations of RFP and Venus fluorescent proteins. C, Cells were cotransfected with wild-type and T1128C NPY prohormones. The cumulative distributions indicate that granules contain higher levels of L7P prohormone $(\boldsymbol{B})$ and T1128C NPY prohormone $(\boldsymbol{C})$. ( $\boldsymbol{B}$ and $\boldsymbol{C}$ each show individual experiments; $n=200$ puncta from 10 cells, bin width $0.01 ;$ NS, not significant; ${ }^{* *} p<0.01,{ }^{*} p<0.05$, Kolmogorov-Smirnov test).

in polarized neurons. We could not routinely distinguish single granules when neurons were cotransfected with wt NPY-RFP plus L7P NPY-Venus. However, the cumulative fluorescence distribution of varicosities was green shifted compared with the control (wt NPY-Venus plus wt NPY-RFP) (supplemental Fig. 4, available at www.jneurosci.org as supplemental material). This suggests that the SNP has a similar effect on prohormone packaging in both AtT-20 cells and hippocampal neurons.

\section{Expression of L7P prohormone leads to increased peptide secretion}

To investigate whether the T1128C polymorphism affected NPY secretion, we measured peptide release from chromaffin cells. These cells endogenously express and secrete NPY (Henion and Landis, 1990; Whim, 2006). To confirm these cells could synthe- size wild-type and mutant prohormone, chromaffin cells were transfected with wt NPY-Venus or T1128C NPY-Venus. In both cases, the fluorescence was punctate (data not shown), consistent with earlier observations (Whim, 2006), suggesting localization to dense core granules.

To monitor peptide secretion, we used FMRFamide tagging (Whim and Moss, 2001). In this technique, the coding sequence for a small peptide, FMRFamide, is added to the NPY prohormone. The release of FMRFamide activates the ionotropic FMRFamide receptors that are expressed on the surface of the same cell. Because FMRFamide and NPY are packaged in the same dense core granules, the release of FMRFamide is a surrogate for the release of NPY (Whim and Moss, 2001). We determined that FMRFamide-ir colocalized with punctate wt NPY-Venus and T1128C-Venus in transfected AtT-20 cells (Fig. 4A). This con- 
firmed that FMRFamide was in the NPYcontaining dense core granules.

Chromaffin cells were then transfected with either the T1128C or wt NPY prohormone. To evoke secretion, cells were stimulated with a train of depolarizations. Peptidergic secretory events were recorded from both types of cells (Fig. 4B). These secretory events indicate that NPYcontaining granules had fused with the cell membrane. The mean peptidergic secretory event was larger from cells expressing the T1128C NPY prohormone compared with the wt NPY prohormone (72 $\pm 32 \mathrm{pA}$ vs $29 \pm 9 \mathrm{pA}$, mean $\pm \mathrm{SD}, n=4$ separate cultures, $14-17$ cells per genotype, $p<$ 0.05 ) (Fig. 4C). However, there was no difference in the response to exogenous application of $200 \mathrm{~nm}$ FMRFamide between the T1128C and wt-NPY-expressing cells $(-332 \pm 127 \mathrm{pA}$ vs $-421 \pm 170 \mathrm{pA}$, mean \pm SEM, $n \geq 5$ cells, $p=0.69$ ). Thus, the increased event amplitude was not attributable to a difference in FMRFamide receptor expression. The cumulative distribution of the amplitude of the release events from cells expressing T1128C was significantly right shifted (Fig. 4D) compared with the wild-type NPY prohormone. The effect on secretion can also be seen in an amplitude histogram (Fig. 4E). This result is consistent with an increase in peptide secretion from the cells expressing the mutant NPY prohormone.

\section{Discussion}

Here, we investigated the consequences of the T1128C single nucleotide polymorphism. Our primary conclusion is that it does not prevent synthesis of NPY but actually leads to an increase in the levels of prohormone and elevated peptide secretion.

In transfected endocrine cells, wild-type and mutant NPY prohormones entered the regulated secretory pathway and were copackaged in the same dense core granules. Nevertheless, when peptide levels were quantified, individual granules apparently contained more mutant prohormone. This is consistent with the observation that cells expressing the mutant prohormone had elevated levels of peptide secretion. This gain-of-function is in contrast to the majority of mutations described in other prohormones which generally lead to misprocessing (Karaplis et al., 1995; Egan et al., 2003).

How might the T1128C polymorphism produce these changes? When proline is inserted in a signal sequence, it can lead to suppression of synthesis or secretion (Nakajima et al., 1999). Eukaryotic signal sequences typically contain an N-terminal hydrophilic region, a hydrophobic core, and a polar $\mathrm{C}$ terminus. The L7P SNP in NPY falls on the hydrophilic-hydrophobic border. In silico analysis using SignalP (Bendtsen et al., 2004) suggests the L7P polymorphism would not prevent signal sequence recognition (data not shown). This is consistent with in vitro translation experiments (Ding et al., 2005) and the regulated secretion that we have observed. However, it is becoming clear that
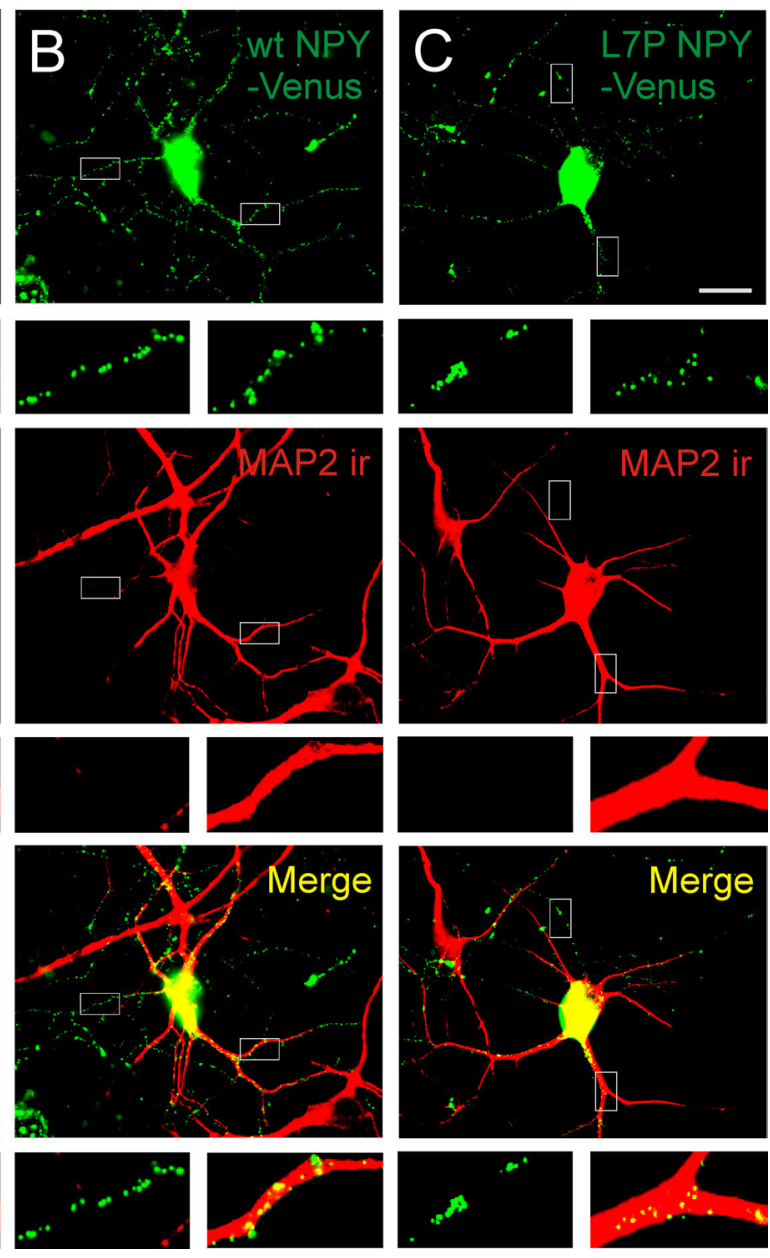

Merge
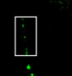

$\therefore$
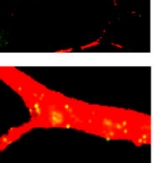

Figure 3. Wild type and L7P NPY-Venus are similarly targeted in polarized hippocampal neurons. $A$, Endogenous NPY distribution, revealed by NPY-ir, was localized to dendritic (MAP2-positive) and axonal (MAP2-negative) processes. $\boldsymbol{B}$, Neurons transfected with wt NPY-Venus had punctate expression in both dendritic and axonal regions. C, Neurons transfected with L7P NPY-Venus had a similar prohormone distribution to cells expressing endogenous NPY or wt NPY-Venus. Insets show examples of MAP2-positive and MAP2-negative processes. Scale bar, $20 \mu \mathrm{m}$.

the role of the signal sequence is not limited to interaction with the signal recognition particle (which ensures delivery of the polypeptide chain to the endoplasmic reticulum). Signal sequences are apparently multifunctional and can regulate the location of the mature protein, the efficiency of ER translocation, and may even have an independent function after cleavage from the pro-protein (Hegde and Bernstein, 2006).

The T1128C polymorphism exchanges the most common leucine codon for the least frequently used proline codon. Nonoptimal codons can lead to translational pausing so enabling correct protein folding and thus indirectly lead to increased synthesis (Zalucki and Jennings, 2007). However, we found a similar phenotype when we expressed optimal or nonoptimal proline codons in the NPY prohormone. This suggests that codon usage does not explain the increased packaging and secretion of the mutant NPY prohormone.

Although polymorphisms have been identified in a number of peptide prohormones, these are generally associated with a loss-offunction phenotype (Peyron et al., 2000; Egan et al., 2003). For example, the L16R mutation in the hypocretin signal sequence that was identified in a case of severe narcolepsy leads to inefficient prohormone cleavage and retention in the soma (Peyron et al., 2000).

In contrast, the expression of the T1128C polymorphism leads 

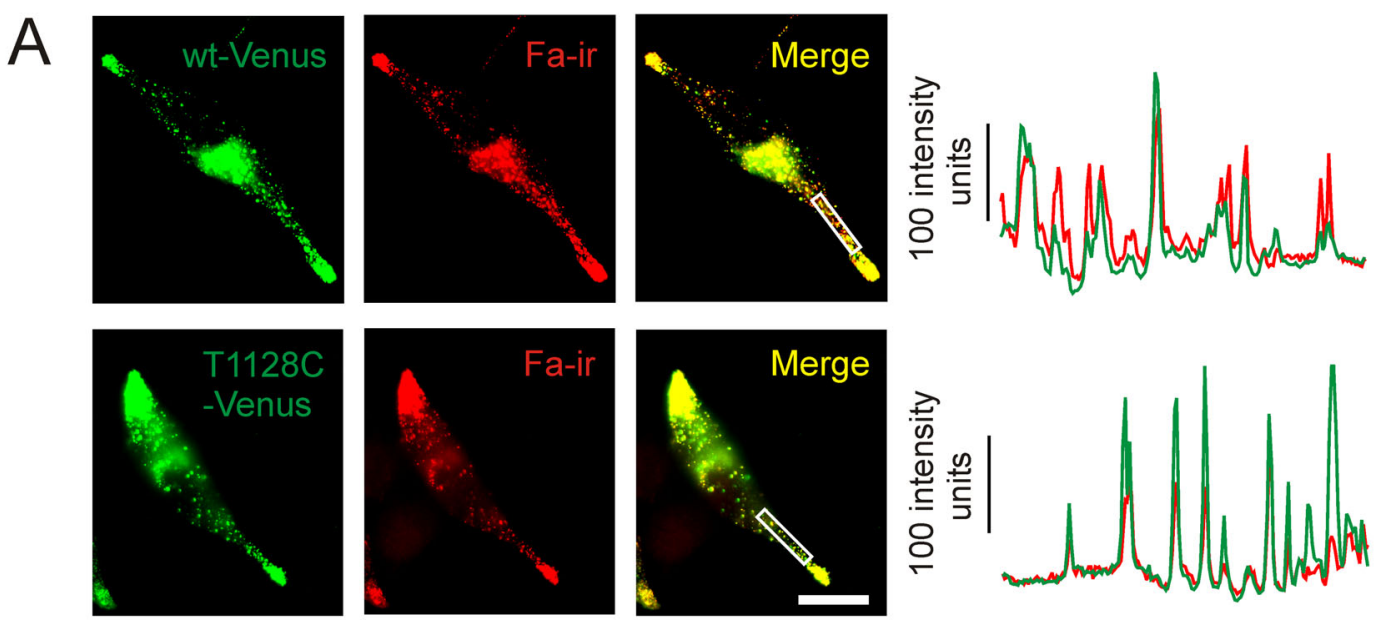
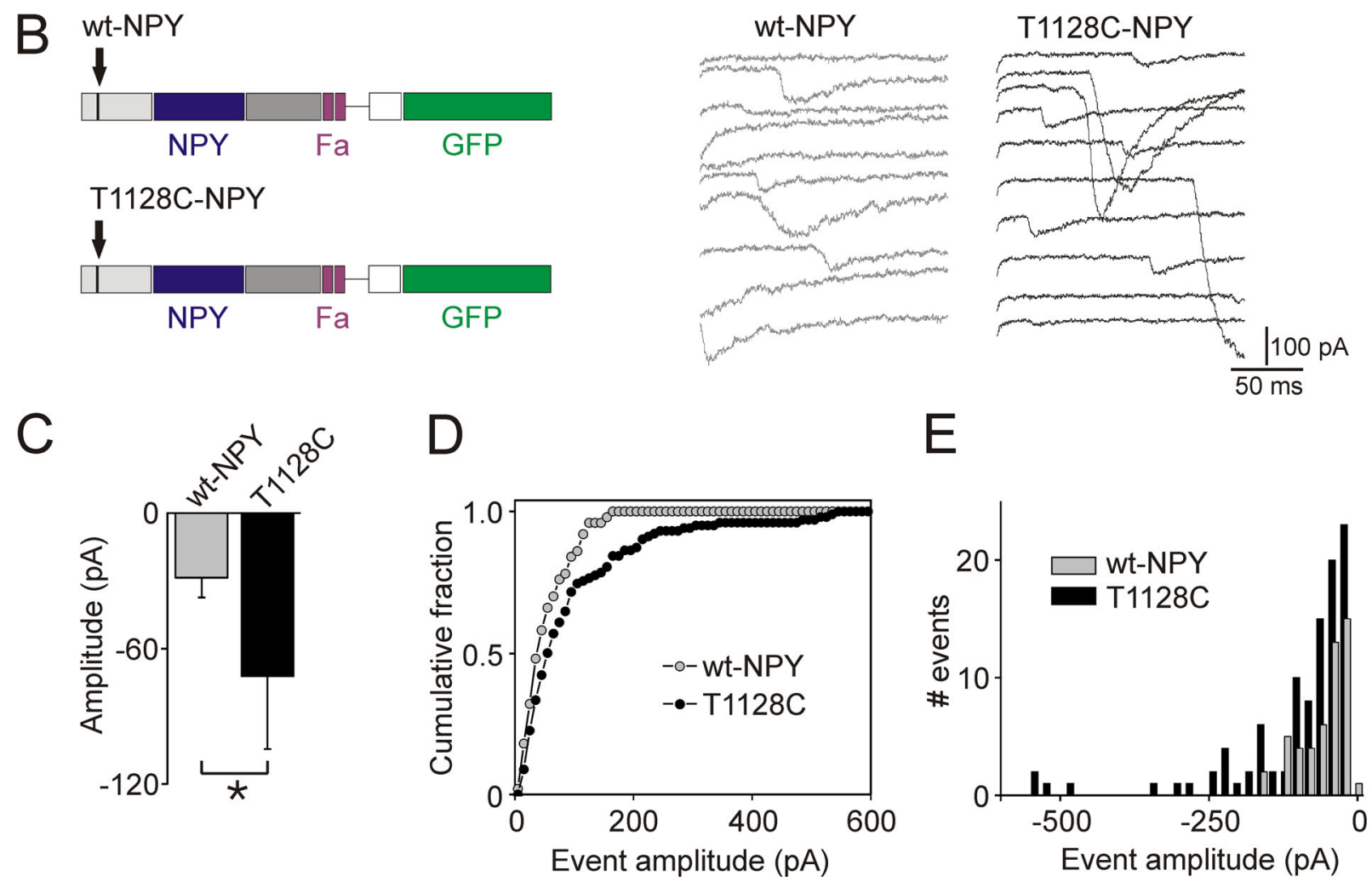

Figure 4. Neuropeptide Y polymorphism is associated with an increase in neuropeptide secretion. A, AtT-20 cells transfected with wt NPY-Venus and T1128C NPY-Venus prohormone. Both constructs also encoded the FMRFamide peptide. Colocalization of NPY-Venus and Fa-ir indicates that these peptides are copackaged. Line scans (right) taken through the center of the boxed regions. Scale bar, $20 \mu \mathrm{m}$. B, Peptide release was detected using FMRFamide tagging. Left, Schematic of IRES constructs, leading to cytoplasmic GFP expression and granular expression of NPY and FMRFamide. Middle and right, Examples of peptidergic secretory events. Secretion was evoked with a depolarization from -80 to $0 \mathrm{mV}$ for $20 \mathrm{~ms}$ repeated $200 \times$ at $5 \mathrm{~Hz}$. C, The average peptidergic secretory current was larger in cells expressing the T1128C-NPY prohormone (mean \pm SD, $n=4$ separate cultures, $14-17$ cells per genotype, $p<0.05$, single-factor ANOVA). $\boldsymbol{D}$, The cumulative distribution of peptidergic secretory events from cells expressing the T1128C-NPY prohormone was significantly right shifted compared with cells expressing the wild-type NPY prohormone (wt-NPY 50 events, T1228C-NPY 102 events, $p<0.01$ Kolmogorov-Smirnov test). $\boldsymbol{E}$, Amplitude histogram of the secretory events shown in $\boldsymbol{D}$.

to an increase in NPY synthesis and secretion. This is consistent with the elevated plasma levels of NPY found in T1128C carriers during exercise and elevated sympathetic activity (Kallio et al., 2001). Although the polymorphism is associated with altered levels of serum cholesterol and triglycerides (Karvonen et al., 1998), the relationship between NPY and lipid metabolism is complex. NPY inhibits lipolysis (Turtzo et al., 2001), but elevation in NPY signaling positively regulates stress-induced obesity (Kuo et al., 2007b).
In conclusion, our experiments demonstrate that the L7P polymorphism leads to an increase in peptide synthesis and secretion. They also emphasize that functional SNPs can have readily detectable effects at the level of single granules.

\section{References}

Bendtsen JD, Nielsen H, von Heijne G, Brunak S (2004) Improved prediction of signal peptides: SignalP 3.0. J Mol Biol 340:783-795.

Castle AM, Huang AY, Castle JD (1997) Passive sorting in maturing gran- 
ules of AtT-20 cells: the entry and exit of salivary amylase and proline-rich protein. J Cell Biol 138:45-54.

Dickerson IM, Dixon JE, Mains RE (1987) Transfected human neuropeptide Y cDNA expression in mouse pituitary cells. Inducible high expression, peptide characterization, and secretion. J Biol Chem 262:13646-13653.

Dikeakos JD, Reudelhuber TL (2007) Sending proteins to dense core secretory granules: still a lot to sort out. J Cell Biol 177:191-196.

Ding B, Kull B, Liu Z, Mottagui-Tabar S, Thonberg H, Gu HF, Brookes AJ, Grundemar L, Karlsson C, Hamsten A, Arner P, Ostenson CG, Efendic S, Monné M, von Heijne G, Eriksson P, Wahlestedt C (2005) Human neuropeptide $\mathrm{Y}$ signal peptide gain-of-function polymorphism is associated with increased body mass index: possible mode of function. Regul Pept 127:45-53.

Egan MF, Kojima M, Callicott JH, Goldberg TE, Kolachana BS, Bertolino A, Zaitsev E, Gold B, Goldman D, Dean M, Lu B, Weinberger DR (2003) The BDNF val66met polymorphism affects activity-dependent secretion of BDNF and human memory and hippocampal function. Cell $112: 257-269$

Fricker LD (1988) Carboxypeptidase E. Annu Rev Physiol 50:309-321.

Hasan KN, Shoji M, Sugimoto K, Tsutaya S, Matsuda E, Kudo R, Nakaji S, Suda T, Yasujima M (2007) Association of novel promoter single nucleotide polymorphisms in vasopressin V1a receptor gene with essential hypertension in nonobese Japanese. J Hum Hypertens 21:825-827.

Hegde RS, Bernstein HD (2006) The surprising complexity of signal sequences. Trends Biochem Sci 31:563-571.

Henion PD, Landis SC (1990) Asynchronous appearance and topographic segregation of neuropeptide-containing cells in the developing rat adrenal medulla. J Neurosci 10:2886-2896.

Higuchi H, Yang HY, Sabol SL (1988) Rat neuropeptide Y precursor gene expression. mRNA structure, tissue distribution, and regulation by glucocorticoids, cyclic AMP, and phorbol ester. J Biol Chem 263:6288-6295.

Kallio J, Pesonen U, Kaipio K, Karvonen MK, Jaakkola U, Heinonen OJ, Uusitupa MI, Koulu M (2001) Altered intracellular processing and release of neuropeptide $\mathrm{Y}$ due to leucine 7 to proline 7 polymorphism in the signal peptide of preproneuropeptide $Y$ in humans. Faseb J 15:1242-1244.

Karaplis AC, Lim SK, Baba H, Arnold A, Kronenberg HM (1995) Inefficient membrane targeting, translocation, and proteolytic processing by signal peptidase of a mutant preproparathyroid hormone protein. J Biol Chem 270:1629-1635.

Karvonen MK, Pesonen U, Koulu M, Niskanen L, Laakso M, Rissanen A, Dekker JM, Hart LM, Valve R, Uusitupa MI (1998) Association of a leucine(7)-to-proline(7) polymorphism in the signal peptide of neuropeptide $\mathrm{Y}$ with high serum cholesterol and LDL cholesterol levels. Nat Med 4:1434-1437.

Kessler MS, Murgatroyd C, Bunck M, Czibere L, Frank E, Jacob W, Horvath C, Muigg P, Holsboer F, Singewald N, Spengler D, Landgraf R (2007) Diabetes insipidus and, partially, low anxiety-related behaviour are linked to a SNP-associated vasopressin deficit in LAB mice. Eur J Neurosci 26:2857-2864.

Kuo LE, Abe K, Zukowska Z (2007a) Stress, NPY and vascular remodeling: Implications for stress-related diseases. Peptides 28:435-440.

Kuo LE, Kitlinska JB, Tilan JU, Li L, Baker SB, Johnson MD, Lee EW, Burnett
MS, Fricke ST, Kvetnansky R, Herzog H, Zukowska Z (2007b) Neuropeptide $\mathrm{Y}$ acts directly in the periphery on fat tissue and mediates stressinduced obesity and metabolic syndrome. Nat Med 13:803-811.

Larson MG, Atwood LD, Benjamin EJ, Cupples LA, D’Agostino RB Sr, Fox CS, Govindaraju DR, Guo CY, Heard-Costa NL, Hwang SJ, Murabito JM, Newton-Cheh C, O'Donnell CJ, Seshadri S, Vasan RS, Wang TJ, Wolf PA, Levy D (2007) Framingham Heart Study 100K project: genome-wide associations for cardiovascular disease outcomes. BMC Med Genet 8 Suppl 1:S5.

Mazei-Robison MS, Couch RS, Shelton RC, Stein MA, Blakely RD (2005) Sequence variation in the human dopamine transporter gene in children with attention deficit hyperactivity disorder. Neuropharmacology 49:724-736.

Nakajima T, Cheng T, Rohrwasser A, Bloem LJ, Pratt JH, Inoue I, Lalouel JM (1999) Functional analysis of a mutation occurring between the two inframe AUG codons of human angiotensinogen. J Biol Chem 274:35749-35755.

Nakamura N, Rabouille C, Watson R, Nilsson T, Hui N, Slusarewicz P, Kreis TE, Warren G (1995) Characterization of a cis-Golgi matrix protein, GM130. J Cell Biol 131:1715-1726.

Niskanen L, Karvonen MK, Valve R, Koulu M, Pesonen U, Mercuri M, Rauramaa R, Töyry J, Laakso M, Uusitupa MI (2000) Leucine 7 to proline 7 polymorphism in the neuropeptide $\mathrm{Y}$ gene is associated with enhanced carotid atherosclerosis in elderly patients with type 2 diabetes and control subjects. J Clin Endocrinol Metab 85:2266-2269.

Peyron C, Faraco J, Rogers W, Ripley B, Overeem S, Charnay Y, Nevsimalova S, Aldrich M, Reynolds D, Albin R, Li R, Hungs M, Pedrazzoli M, Padigaru M, Kucherlapati M, Fan J, Maki R, Lammers GJ, Bouras C, Kucherlapati R, et al. (2000) A mutation in a case of early onset narcolepsy and a generalized absence of hypocretin peptides in human narcoleptic brains. Nat Med 6:991-997.

Sobota JA, Ferraro F, Bäck N, Eipper BA, Mains RE (2006) Not all secretory granules are created equal: partitioning of soluble content proteins. Mol Biol Cell 17:5038-5052.

Turtzo LC, Marx R, Lane MD (2001) Cross-talk between sympathetic neurons and adipocytes in coculture. Proc Natl Acad Sci USA 98:12385-12390.

Ukkola O, Kesäniemi YA (2007) Leu7Pro polymorphism of PreproNPY associated with an increased risk for type II diabetes in middle-aged subjects. Eur J Clin Nutr 61:1102-1105.

Vitko I, Chen Y, Arias JM, Shen Y, Wu XR, Perez-Reyes E (2005) Functional characterization and neuronal modeling of the effects of childhood absence epilepsy variants of CACNA1H, a T-type calcium channel. J Neurosci 25:4844-4855.

Whim MD (2006) Near simultaneous release of classical and peptide cotransmitters from chromaffin cells. J Neurosci 26:6637-6642.

Whim MD, Moss GW (2001) A novel technique that measures peptide secretion on a millisecond timescale reveals rapid changes in release. Neuron 30:37-50.

Zalucki YM, Jennings MP (2007) Experimental confirmation of a key role for non-optimal codons in protein export. Biochem Biophys Res Commun 355:143-148. 